\title{
Acetylcholine in the orbitofrontal cortex is necessary for the acquisition of a socially transmitted food preference
}

\author{
Robert S. Ross, ${ }^{1}$ jill McGaughy, ${ }^{2}$ and Howard Eichenbaum ${ }^{1,3}$ \\ ${ }^{1}$ Center for Memory and Brain, Psychology Department, Boston University, Boston, Massachusetts, 02215, USA; ${ }^{2}$ Psychology \\ Department, University of New Hampshire, Durham, New Hampshire, 03824, USA
}

\begin{abstract}
The social transmission of food preference task (STFP) has been used to examine the involvement of the hippocampus in learning and memory for a natural odor-odor association. However, cortical involvement in STFP has not been extensively studied. The orbitofrontal cortex (OFC) is important in odor-guided learning, and cholinergic depletion of the entire neocortex results in impairments in STFP. Here we examined the specific role of cholinergic modulation in the OFC by assessing the effect of 192 immunoglobulin G-saporin infusion directly into OFC prior to training on STFP. Cholinergic depletion in the OFC impaired expression of the socially transmitted odor association measured $2 \mathrm{~d}$ after training, indicating that cholinergic function in the OFC is essential for this form of associative learning.
\end{abstract}

Following social interaction with a conspecific that has recently eaten, rodents will subsequently prefer the same food as ingested by that peer. In the wild, it is thought that this interaction and subsequent food preference allows rodents to lessen the risk of eating novel foods because a food recently eaten by other, healthy rats is apparently safe (Galef 1986). This naturally occurring social transmission of food preference (STFP) has been modified for the laboratory setting, allowing researchers to explore the behavioral and brain mechanisms of this naturalistic form of memory. In these studies, a subject rat interacts with a conspecific ("demonstrator") rat that has recently eaten an odorous food, typically powdered rat chow mixed with a particular household spice. During this exposure, the subject rat forms an association between the odorous food and carbon disulfide, a natural and volatile constituent of a rat's breath (Galef et al. 1988). Subsequent to this social learning episode, subjects will choose to eat more of the food previously eaten by the demonstrator in preference to another, even equally familiar, food (Galef et al. 1985). Damage to the hippocampus prior to, or shortly after, training sessions results in impairment in STFP (Winocur 1990; Bunsey and Eichenbaum 1995; Alvarez et al. 2001; Winocur et al. 2001; Clark et al. 2002). The involvement of other brain areas and, in particular, of olfactory cortical areas in STFP has not been extensively studied.

The orbitofrontal cortex (OFC) receives strong olfactory inputs from the piriform cortex and medial thalamus (Price et al. 1991) and is important for olfactory learning and memory (Petrulis and Eichenbaum 2003). The OFC is also reciprocally connected with the medial temporal lobe, including the perirhinal and entorhinal cortices (Deacon et al. 1983; Price et al. 1991; Barbas 2000), which play a key role in learning and memory (Eichenbaum 2000), including STFP (Alvarez et al. 2001).

Damage to the OFC results in impairments in learning difficult olfactory discriminations (Eichenbaum et al. 1980, 1983) and alters olfactory-guided sexual behaviors in hamsters (Salpolsky and Eichenbaum 1980). OFC lesions retard acquisition of an

\section{${ }^{3}$ Corresponding author.}

E-mail hbe@bu.edu; fax (617) 353-1414.

Article published online ahead or print. Article and publication date are at http://www.learnmem.org/cgi/doi/10.1101/lm.91605. odor-cued delay nonmatch to sample task (Otto and Eichenbaum 1992). The OFC is also important for the acquisition of odorplace associations (Lipton et al. 1999), odor-tactile associations (Whishaw et al. 1992), and odor-taste associations (Critchley and Rolls 1996; Rolls 1997). Because STFP also relies on an odor-odor association (Galef et al. 1988), the OFC may also make a critical contribution to this naturalistic form of associative learning.

Cortical acetylcholine (ACh) plays a central role in learning and memory (Kopelman 1986; Hagan and Morris 1989; Hasselmo and Bower 1993; Hasselmo 1999; Hasselmo and McGaughy 2004). Of particular importance to the current experiment, the role of cholinergic innervation of the neocortex has been studied in the context of acquisition of STFP (BergerSweeney et al. 2000; Vale-Martinez et al. 2002). In these studies, the selective cholinergic toxin 192 immunoglobulin G (IgG)saporin was injected into the nucleus basalis/substantia innominata (NBM/SI) region of the basal forebrain before training. 192 IgG-saporin lesions of the NBM/SI produced robust impairments in STFP performance, indicating that cholinergic projections originating in NMB/SI are critical to STFP. However, because 192 IgG-saporin lesions of the NBM/SI target virtually all areas of the neocortex, these studies did not elucidate which of the terminal fields of the NBM/SI are most important to this behavior (Bigl et al. 1982; Mesulam et al. 1983). In the present study, we used 192 IgG-saporin lesions restricted to the OFC to determine whether cholinergic mechanisms in OFC specifically are critical to the acquisition of STFP.

\section{Results}

Six rats received injections of $0.5 \mu \mathrm{L} 192$ IgG-saporin in the OFC (hence called OFC-AChX rats), and six other rats served as sham operated controls. Ten days following the surgery, subjects were exposed to demonstrator rats and 2 d later tested for food preferences. Sham control subjects ate more of the trained food $(4.29 \pm 0.97 \mathrm{~g}[\mathrm{SEM}])$ than the comparison food $(0.79 \pm 0.27 \mathrm{~g}$; paired samples $t$-test; $t_{(5)}=3.987, P=0.01$ ) (Fig. 1A). Sham controls therefore demonstrated a strong preference for the trained food, which constituted $84.2 \pm 4.8 \%$ (SEM) of the total food eaten (Fig. 1B), a proportion significantly greater than chance $\left(t_{(5)}=7.167, P=0.001\right)$. In contrast OFC-AChX rats ate no more 
A.

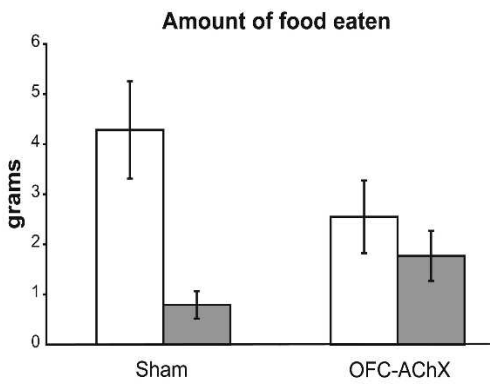

B.

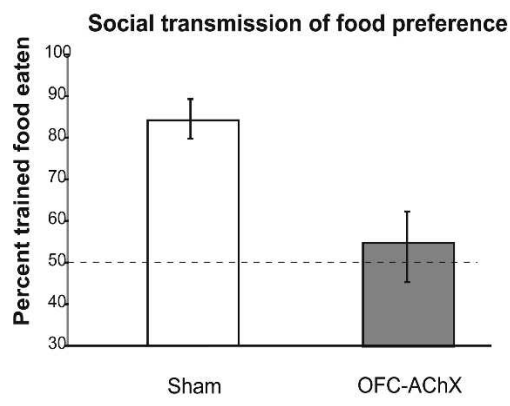

C.

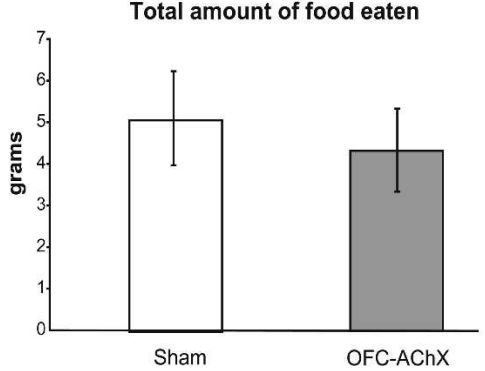

Figure 1. (A) Amount of trained food eaten (white bar) for each group in grams vs. amount of comparison food eaten (dark bar) during testing period. (B) Performance by OFC-AChX rats (dark bar) and sham operated controls (white bar) in STFP. The dashed line indicates chance selection of the two foods. (C) Total amount of food eaten by each group in grams. Data are represented as mean \pm SEM.

of the trained food $(2.55 \pm 0.73)$ than the comparison food $\left(1.78 \pm 0.50\right.$; paired samples $t$-test; $\left.t_{(5)}=1.044, P>0.05\right)$ (Fig. 1A). OFC-AChX rats therefore did not demonstrate a preference for the trained food, which constituted only $54.9 \pm 8.2 \%$ of the total food eaten (Fig. 1B), a proportion not significantly different from chance selection of the two foods (one sample $t$-test; $\left.t_{(5)}=0.596, P>0.05\right)$. Accordingly, OFC-AChX rats were significantly impaired compared with sham control rats in STFP. The difference in the amount of trained versus comparison food eaten by the controls was greater than that in the OFC-AChX group, as indicated by significant interaction in the repeatedmeasures ANOVA on amounts of food eaten $\left(F_{(1,1)}=5.622\right.$, $P=0.039$ ) (Fig. 1A) and in a comparison between percentages of trained food eaten between groups $\left(t_{(10)}=3.081, P=0.012\right)$ (Fig. 1B). The group difference in trained preference occurred in the absence of a group difference in the total amount of food eaten $\left(4.32 \pm 1.0\right.$ g vs. $\left.5.07 \pm 1.12 \mathrm{~g} ; t_{(10)}=0.497, P>0.05\right)$ (Fig. $1 \mathrm{C}$ ).

Acetylcholinesterase-positive (AChE+) fibers were counted to confirm the effectiveness of 192 IgG-saporin in the OFC. Areas within the OFC were examined bilaterally at 4.70, 3.70, and 2.70 $\mathrm{mm}$ anterior to bregma. The number of AChE+ fibers in the OFCAChX group compared with fiber counts in the sham control group were decreased by $35.09 \%, 25.42 \%$, and $27.99 \%$, respectively, in each of these areas, and each of these decreases was significant (independent $t$-tests at each rostral to caudal site: $t_{(10)}=9.746, P<0.001 ; t_{(10)}=3.210, P=0.009 ; t_{(10)}=3.706$, $P=0.004$ ) (Fig. 2). Figure 3 shows a representative example of the AChE depletion seen in the OFC $2.70 \mathrm{~mm}$ anterior to bregma.

Reference areas in the cingulate cortex and agranular insular cortex on the same brain sections were also examined to determine the spread of 192 IgG-saporin-induced fiber loss (Fig. 2). There were no significant differences in AChE+ fiber counts between the OFC-AChX group and sham controls in the cingulate cortex (rostral to caudal: $t_{(10)}=0.193, P>0.05 ; t_{(10)}=1.947$, $P>0.05 ; t_{(10)}=0.940, P>0.05$ ) (Fig. 2) or the agranular insular cortex $\left(t_{(10)}=0.025, P>0.05\right)$ (Fig. 2).

\section{Discussion}

Here we observed that cholinergic deafferentation of the OFC prevents STFP, supporting the hypothesis that ACh in the OFC is essential for this naturalistic form of odor-odor association. It is unlikely that the observed deficit in STFP is secondary to an impairment in olfactory detection or discrimination. In a previous study, OFC-AChX rats normally acquired odor discriminations (McAlonan and Brown 2003). OFC ablation does not prevent acquisition of simple olfactory discriminations but does impair higher-order olfactory learning, including reversal learning, acquisition of task rules, and complex associations (Eichenbaum et al. 1980, 1983; Otto and Eichenbaum 1992; Lipton et al. 1999; Schoenbaum et al. 1999). It is also unlikely that the STFP deficit was due to deficits in taste since there was no damage seen in the agranular insular cortex.

Winocur and Moscovitch (1999) previously reported that aspiration lesions of the frontal cortex do not impair STFP when only two food choices are presented in the critical choice test. However, the frontal cortex damage in the Winocur and Moscovitch (1999) study was sustained largely within the primary and secondary motor cortex, with some damage in cingulate cortex. The site of cortical damage in that study was also more caudal and dorsal than was the effective site of OFC damage reported here.

Loss of cholinergic function in the OFC may contribute to a learning deficit in STFP by preventing OFC networks from establishing the critical association between the odorous food and the odor of carbon disulfide. Lesions of the OFC also impair the formation of odor-tactile (Whishaw et al. 1992) and odor-taste (Critchley and Rolls 1996; Rolls 1997) associations. Also, OFC cells fire selectively in response to particular odor-place associations (Lipton et al. 1999). Thus, an explanation of the present results is that the deficit in STFP following OFC lesions is a reflection of a general disorder in stimulus association normally mediated by OFC. The present results suggest that cholinergic mechanisms are central to this associative function.

ACh may play a pervasive role in learning and memory. A cholinergic lesion produced in the NBM/SI by 192 IgG-saporin impairs the performance of rats in delayed-nonmatch to position (Dornan et al. 1996), passive avoidance learning (Zhang et al. 1996), inhibitory avoidance learning (Power et al. 2002) and STFP (Berger-Sweeney et al. 2000; Vale-Martinez et al. 2002). In accounting for these findings, Hasselmo and McGaughy (2004) proposed that high ACh levels in the cortex are necessary to set the appropriate dynamics for attention and encoding. They theorized that ACh enhances the cellular response to incoming sensory input in the cortex while at the same time decreases the possibility of interference from any previously formed cortical 
A.

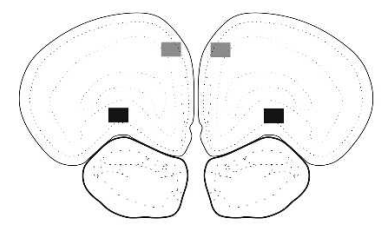

AP 4.70

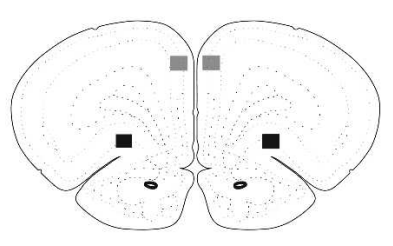

AP 3.70

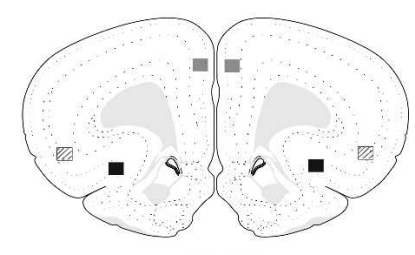

AP 2.70

B.

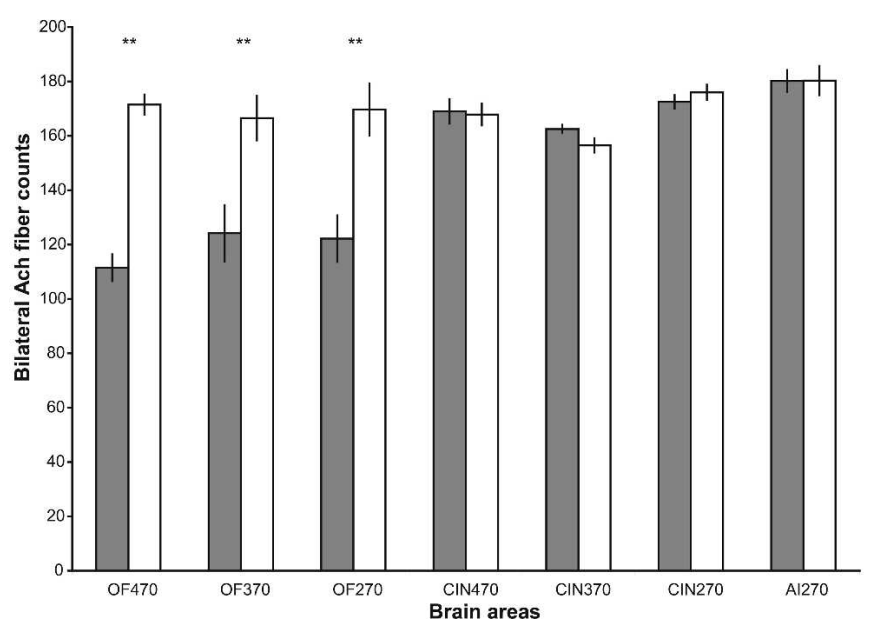

Figure 2. (A) Highlighted squares (black for orbitofrontal cortex [OFC], gray for cingulate cortex [CIN], and stripes for agranular insular cortex [AI]) represent areas where AChE+ fibers were counted in sham operated controls and in animals with $192 \mathrm{lgG}$-saporin lesions. Numbers represent AP coordinates relative to bregma (Paxinos and Watson 1998). (B) Bilateral AChE+ fiber counts in all areas examined. Dark bars show counts from OFC-AChX rats, and white bars show counts from sham operated controls. Group labels indicate loci in OFC, CIN, and Al at AP coordinates relative to bregma. Data are represented as mean counts \pm SEM. ${ }^{* *}$ Significant difference $(P<0.01)$ in fiber counts between lesion and control group.

representations (Hasselmo and McGaughy 2004). If this hypothesis is correct, then decreasing the amount of cortical ACh should affect the ability to encode new information such as an odorodor association. The present results, showing that depletion of $\mathrm{ACh}$ in the OFC prevents the encoding of the new information necessary for STFP, support this hypothesis.

An alternative possibility is the learning impairment observed here is due to an attentional deficit rather than an impairment in encoding new associations. Lesions of the NBM/SI have been shown to impair sustained (McGaughy et al. 1996) and divided attention (Turchi and Sarter 1997), but these lesions deplete the cholinergic innervation of the entire neocortical mantle. In contrast, neither excitotoxic (Birrell and Brown 2000) nor cholinotoxic lesions (McAlonan and Brown 2003) of the OFC impair selective attention or prevent the initial formation of stimulus-response associations. Thus it is unlikely that the learning impairment observed here is secondary to a deficit in attention.

Though projections from the NBM/SI have previously been shown to be important in the STFP task (Berger-Sweeney et al. 2000; Vale-Martinez et al. 2002), the NBM/SI provides ACh input to most of the neocortex (Bigl et al. 1982; Mesulam et al. 1983). The present study expands on these findings, showing that a relatively small ACh lesion of the OFC impairs performance in the STFP task. This implies that ACh in the OFC is required for acquiring a socially transmitted food preference.

\section{Materials and Methods}

\section{Subjects}

Subjects were 16 Long-Evans male rats (Harlan Sprague-Dawley, IN) weighing 250-275 $\mathrm{g}$ at the beginning of the study. They were housed singly in polypropylene cages and kept on a 12-h dark/12-h light cycle with ad libitum access to food (Purina rat chow 5001) and water. Six additional Long-Evans male rats weighing $225-250 \mathrm{~g}$ at the beginning of the study served as demonstrator rats; these animals were housed in groups of three. All animals underwent extensive handling for $\sim 5$ min daily over at least $2 \mathrm{wk}$.

\section{IgG-saporin lesions}

Nine subjects were anesthetized with halothane $(2 \%)$ and nitrous oxide/ oxygen (7:3) throughout the surgery. Body temperature was maintained at $37^{\circ} \mathrm{C}$ by using a heating pad, and atropine sulfate $(0.081 \mathrm{mg})$ was intraperitoneally injected to prevent respiratory complications. The rat's head was shaved and was placed in a stereotaxic instrument (Kopf Instruments), and the tooth bar was set to -3.3 . The skull was exposed by a midline incision, and two holes were drilled in the skull. A Hamilton syringe was lowered to the following OFC coordinates: anteroposterior $(\mathrm{AP})+4.7$, mediolateral $(\mathrm{ML}) \pm 1.8$, dorsoventral (DV) - 4.0. Before the infusion, the needle was left in place for 4 min to allow bleeding to subside, after which injections began. At each site 0.5 $\mu \mathrm{L}$ of 192 IgG-saporin (Advanced Targeting Systems) was infused at $0.25 \mu \mathrm{L} /$ min by using a microinjection pump (World Precision Instruments) and a $10 \mu \mathrm{L}$ Hamilton syringe. Subsequently, the needle was again allowed to sit for 4 min before being raised. The skin was then sutured, and a topical antibiotic was administered to prevent infection. Sham operated animals underwent the same procedure, except that the needle was lowered into the brain at the target coordinates and allowed to sit for $10 \mathrm{~min}$ with no injection being given. Animals were allowed to recover for 10 $\mathrm{d}$ before training. Two animals were eliminated from the study because they received only unilateral lesions.

\section{STFP task}

Training followed the procedure described by Alvarez et al. (2001). Animals were handled for $2 \mathrm{wk}$, habituated to the testing room, and trained to eat powdered rat chow (Purina rat chow $5001)$ out of metal cups $(4.5 \mathrm{~cm}$ height, $7.5 \mathrm{~cm}$ diameter, $3 \mathrm{~cm}$ opening; Lab Products). After handling and habituation, animals were food deprived the day prior to training by allowing access to four food pellets in the previous $24 \mathrm{~h}$. On the training day, all animals were allowed to habituate to the test room for $10 \mathrm{~min}$. Then demonstrator rats were given access to odorant-scented chow for 30 min with access to water. Demonstrator rats were required to eat at least $1 \mathrm{~g}$ of food and were then placed in the home cage of a subject, where the animals were allowed to interact for $20 \mathrm{~min}$ without any barrier between them. This procedure was repeated twice at 1-h intervals, each time using a different demonstrator who had eaten the same odorant. Half the subjects were trained with thyme-scented food $(1 \%)$, and the other half were trained with basil-scented food $(0.7 \%)$. Some subjects in this experiment had previously been used as demonstra- 

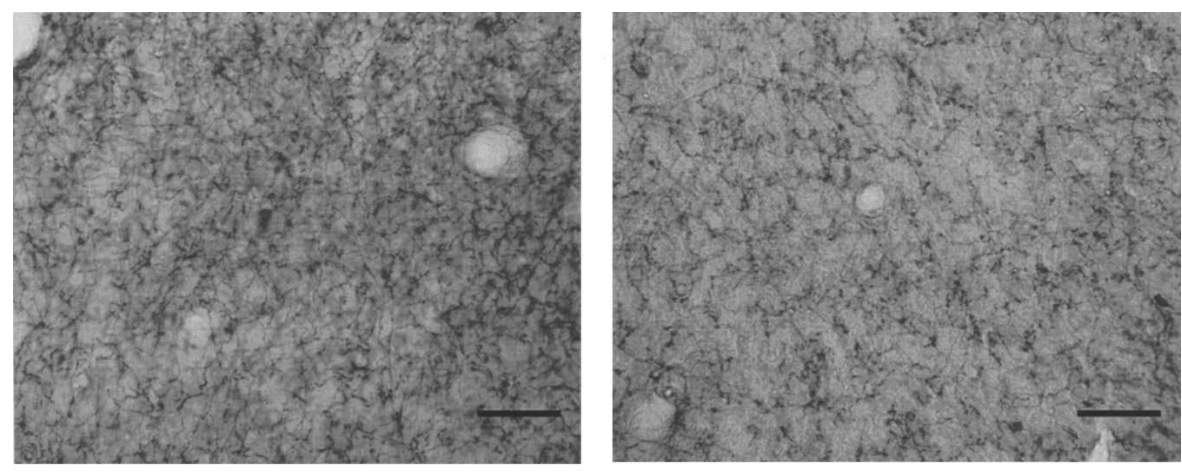

Sham

Lesion

Figure 3. Representative example of $A C h E$ depletion seen in the $192 \mathrm{lgG}$-saporin lesion group in the OFC $2.70 \mathrm{~mm}$ anterior to bregma (line $=50 \mu \mathrm{m}$ ).

tors in a different experiment. However, if the subject had previously served as a demonstrator rat and eaten thyme-scented food, in this experiment they were trained with basil and vice versa.

Food preferences were assessed $2 \mathrm{~d}$ following training. Subjects were food deprived by allowing access to only four food pellets during the previous $24 \mathrm{~h}$. Subjects were tested in the same room that training occurred and were again given $10 \mathrm{~min}$ to habituate prior to testing. Two weighed odorant-scented food cups were then placed into the home cage of the subject with water available. For subjects that were trained with thymescented food, they were given a choice of thyme-scented food or oregano-scented food (1\%). For subjects that were trained with basil-scented food, they were given a choice of basil-scented food or oregano-scented food. Subjects were allowed to eat for $45 \mathrm{~min}$, after which cups were weighed to determine the amount of food eaten. The mean percentage preference score for the trained odor (e.g., thyme) was calculated as follows: (weight of thyme-scented food eaten/weight of all food eaten) $\times 100$. One sham control subject and one OFC-AChX subject were eliminated from the study because they did not eat at least $1 \mathrm{~g}$ of food during the testing period.

\section{Histology}

At the completion of behavioral testing, subject animals were deeply anaesthetized with an overdose of sodium pentobarbital $(100 \mathrm{mg} / \mathrm{kg})$ and were perfused transcardially with $0.9 \%$ saline followed by $10 \%$ formalin. Perfused brains were placed in a $30 \%$ sucrose solution and allowed to sink for cryoprotection. Brains were sectioned on a freezing-sliding microtome at 50- $\mu \mathrm{m}$ thickness and stained to reveal AChE+ fibers. Subsequent sections were also Nissl-stained (thionin) to more easily follow the injection tract. AChE staining was accomplished by using an orbital shaker throughout incubation and rinse periods. Sections were first placed in $0.1 \% \mathrm{H}_{2} \mathrm{O}_{2}$ in phosphate buffer for $30 \mathrm{~min}$ before being rinsed three times for $3 \mathrm{~min}$ each with $0.1 \mathrm{M}$ maleate buffer (pH 6.0). After rinsing, sections were then incubated for $45 \mathrm{~min}$ in a solution of $5 \mathrm{mg}$ acetylthiocholine iodide (Sigma), $0.5 \mathrm{~mL}$ of $0.1 \mathrm{M}$ sodium citrate, $1.0 \mathrm{~mL}$ of $30 \mathrm{mM}$ copper sulfate, $1.0 \mathrm{~mL}$ $\mathrm{dH}_{2} \mathrm{O}$, and $1.0 \mathrm{~mL}$ of $5 \mathrm{mM}$ potassium ferricyanide mixed with $190 \mathrm{~mL}$ of $0.1 \mathrm{M}$ maleate buffer. Sections were then rinsed again three times for $3 \mathrm{~min}$ each in a $50 \mathrm{mM}$ Tris buffer ( $\mathrm{pH} \mathrm{7.6).} \mathrm{A}$ second incubation period was then conducted by using a solution of $0.05 \mathrm{~g}$ diaminobenzidine (DAB) and $0.375 \mathrm{~g}$ nickel ammonium sulfate in $125 \mathrm{~mL}$ of $50 \mathrm{mM}$ Tris buffer. After $10 \mathrm{~min}$ in this solution, 12 drops of $0.1 \% \mathrm{H}_{2} \mathrm{O}_{2}$ in $\mathrm{dH}_{2} \mathrm{O}$ were added until the sections darkened. Sections were then rinsed with $5 \mathrm{mM}$ Tris buffer and mounted on gelatin-coated slides. Sections were allowed to dry overnight, dehydrated in an ascending alcohol series, and defatted in xylene prior to coverslipping. To obtain counts of AChE+ fibers, images of the specific areas examined (Fig. 2) were captured by using a Nikon DXM 1200 digital camera and transferred to Image Pro Plus 4.5 software. By using the Image Pro Plus 4.5 software, $50-\mu \mathrm{m}$ squares were placed over the image, making a six-by-five grid. AChE+-stained fibers that passed under the outside lines of the grid were counted as AChE+.

\section{Statistical analysis}

All statistical analyses were carried out by using SPSS for Windows, version 11 (SPSS). A repeated-measures ANOVA was used to determine if there was a group by food type interaction, with food type representing the amount of trained food and comparison food consumed by each animal. After finding a significant group by food type interaction, paired samples $t$-tests were used to determine which interactions were causing this significance. Independent $t$-tests were used to compare the behavioral performance between groups when expressed as percentages as well as the bilateral AChE+ fiber counts in each brain area examined. Significance levels were set at 0.05 .

\section{Acknowledgments}

We would like to thank Randy Vargas for piloting work on this study. This work was supported by NIA grant AG 09973 to H.E.

\section{References}

Alvarez, P., Lipton, P.A., Melrose, R., and Eichenbaum, H. 2001. Differential effects of damage within the hippocampal region on memory for a natural, nonspatial odor-odor association. Learn. Mem. 8: $79-86$.

Barbas, H. 2000. Connections underlying the synthesis of cognition, memory, and emotion in primate prefrontal cortices. Brain Res. Bull. 52: $319-330$.

Berger-Sweeney, J., Stearns, N.A., Frick, K.M., Beard, B., and Baxter, M.G. 2000. Cholinergic basal forebrain is critical for social transmission of food preferences. Hippocampus 10: 729-738.

Bigl, V., Woolf, N.J., and Butcher, L.L. 1982. Cholinergic projections from the basal forebrain to frontal, parietal, temporal, occipital, and cingulate cortices: A combined fluorescent tracer and acetylcholinesterase analysis. Brain Res. Bull. 8: 727-749.

Birrell, J. and Brown, V. 2000. Medial frontal cortex mediates perceptual attentional set shifting in the rat. J. Neurosci. 20: $4320-4324$.

Bunsey, M. and Eichenbaum, H. 1995. Selective damage to the hippocampal region blocks long-term retention of a natural and nonspatial stimulus-stimulus association. Hippocampus 5: 546-556.

Clark, R.E., Broadbent, N.J., Zola, S.M., and Squire, L.R. 2002. Anterograde amnesia and temporally graded retrograde amnesia for a nonspatial memory task after lesions of hippocampus and subiculum. J. Neurosci. 22: 4663-4669.

Critchley, H.D. and Rolls, E.T. 1996. Olfactory neuronal responses in the primate orbitofrontal cortex: Analysis in an olfactory discrimination task. J. Neurophysiol. 75: 1659-1672.

Deacon, T.W., Eichenbaum, H., Rosenberg, P., and Eckman, K.W. 1983. Afferent connections of the perirhinal cortex in the rat. J. Comp. Neurol. 220: 168-190.

Dornan, W.A., McCampbell, A.R., Tinkler, G.P., Hickman, U., Bananon, A.W., Decker, M.W., and Gunther K.L. 1996. Comparison of site-specific injections into the basal forebrain on water maze and radial arm performance in the male rat after immunolesioning with 192 IgG-saporin. Behav. Brain Res. 82: 93-101.

Eichenbaum, H. 2000. A cortical-hippocampal system for declarative memory. Nat. Rev. Neurosci. 1: 41-50.

Eichenbaum, H., Eckmann, K.W., and Shedlack, K.J. 1980. Thalamocortical mechanisms in odor guided behavior, I: The effects of lesions on the mediodorsal nucleus and frontal cortex on olfactory discrimination in the rat. Brain Behav. Evol. 17: 255-275.

Eichenbaum, H., Clegg, R.A., and Feeley, A. 1983. A re-examination of functional subdivisions of the rodent prefrontal cortex. Exp. Neurol. 79: $434-451$.

Galef, B.G. 1986. Social enhancement of food preferences in Norway 
rats: A brief review. In Social learning in animals: The roots of culture. (eds. C. Heyes and B.G. Galef), pp. 49-64. Academic Press, Burlington, MA.

Galef, B.G., Kennett, D.J., and Stein, M. 1985. Demonstrator influence on observer diet preference: Effects of simple exposure and the presence of a demonstrator. Anim. Learn. Behav. 13: 25-30.

Galef, B.G., Mason, J.R., Preti, G., and Bean, N.J. 1988. Carbon disulfide: A semiochemical mediating socially-induced diet choice in rats. Physiol. Behav. 42: 119-124.

Hagan, J.J., and Morris, R.G.M. 1989. The cholinergic hypothesis of memory: A review of animal experiments. In Psychopharmacology of the aging nervous system (eds. L.L. Iversen and S.H. Snyder), pp. 237-324. Plenum, New York.

Hasselmo, M.E. 1999. Neuromodulation: Acetylcholine and memory consolidation. Trends Cogn. Sci. 3: 351-359.

Hasselmo, M.E. and Bower, J.M. 1993. Acetylcholine and memory. Trends Neurosci. 16: 218-221.

Hasselmo, M.E. and McGaughy, J. 2004. High acetylcholine levels set circuit dynamics for attention and encoding and low acetylcholine levels set dynamics for consolidation. Prog. Brain Res. 145: 207-237.

Kopelman, M.D. 1986. The cholinergic neurotransmitter system in human memory and dementia: A review. Q. J. Exp. Psychol. 38: $535-573$.

Lipton, P.A., Alvarez, P., and Eichenbaum, H. 1999. Crossmodal associative memory representations in rodent orbitofrontal cortex. Neuron 22: 349-359.

McAlonan, K. and Brown, V.J. 2003. Orbital prefrontal cortex mediates reversal learning and not attentional set shifting in the rat. Behav. Brain Res. 146: 97-103.

McGaughy, J., Kaiser, T., and Sarter, M. 1996. Behavioral vigilance following infusions of 192 IgG-saporin into the basal forebrain: Selectivity of the behavioral impairment and relation to cortical AChE-positive fiber density. Behav. Neurosci. 110: 247-265.

Mesulam, M.M., Mufson, E.J., Wainer, B.H., and Levey, A.I. 1983. Central cholinergic pathways in the rat: An overview based on an alternative nomenclature (Ch1-Ch6). Neuroscience 10: 1185-1201.

Otto, T. and Eichenbaum, H. 1992. Complementary roles of the orbital prefrontal cortex and the perirhinal-entorhinal cortices in an odor-guided delayed-nonmatching-to-sample task. Behav. Neurosci. 106: $762-775$.

Paxinos, G. and Watson, C. 1998. The rat brain in stereotaxic coordinates. Academic Press, San Diego, CA.

Petrulis, A. and Eichenbaum, H. 2003. Olfactory memory. In Handbook of olfaction and gustation, Vol. 2 (ed. R.L. Doty), pp. 409-438. Marcel Dekker, New York.
Power, A.E., Thal, L.J., and McGaugh, J.L. 2002. Lesions of the nucleus basilis magnocellularis induced by 192 IgG-saporin block memory enhancement with postraining norepinephrine in the basolateral amygdala. Proc. Natl. Acad. Sci. 99: 2315-2319.

Price, J.L., Carmichael, T., Carnes, K.W., Clugnet, M., Kuroda, M., and Ray, J.P. 1991. Olfactory input to the prefrontal cortex. In Olfaction as a model for computational neuroscience (eds. J. Davis and $\mathrm{H}$. Eichenbaum), pp. 101-120. MIT, Cambridge, MA.

Rolls, E.T. 1997. Taste and olfactory processing in the brain and its relation to the control of eating. Crit. Rev. Neurobiol. 11: 263-287.

Sapolsky, R.M. and Eichenbaum, H. 1980. Thalamocortical mechanisms in odor guided behavior, II: Effects of lesions of the mediodorsal nucleus and frontal cortex on sex behavior and odor preferences in the hamster. Brain Behav. Evol. 17: 275-290.

Schoenbaum, G., Chiba, A.A., and Gallagher, M. 1999. Neural encoding in orbitofrontal cortex and basolateral amygdala during olfactory discrimination learning. J. Neurosci. 19: 1876-1884.

Turchi, J. and Sarter, M. 1997. Cortical acetylcholine and processing capacity: Effects of cortical cholinergic deafferentation on crossmodal divided attention in rats. Brain Res. Cogn. Brain Res. 6: $147-158$

Vale-Martinez, A., Baxter, M.G., and Eichenbaum, H. 2002. Selective lesions of basal forebrain cholinergic neurons produce anterograde and retrograde deficits in a social transmission of food preference task in rats. Eur. J. Neurosci. 16: 983-998.

Whishaw, I.Q., Tomie, J.A., and Kolb, B. 1992. Ventrolateral prefrontal cortex lesions in rats impair the acquisition and retention of a tactile-olfactory configural task. Behav. Neurosci. 106: 597-603.

Winocur, G. 1990. Anterograde and retrograde amnesia in rats with dorsal hippocampal or dorsomedial thalamic lesions. Behav. Brain Res. 38: $145-154$.

Winocur, G. and Moscovitch, M. 1999. Anterograde and retrograde amnesia after lesions to frontal cortex in rats. J. Neurosci. 19: 9611-9617.

Winocur, G., McDonald, R.M., and Moscovitch, M. 2001. Anterograde and retrograde amnesia in rats with large hippocampal lesions. Hippocampus 11: 18-26.

Zhang, Z.J., Berbos, T.G., Wrenn, C.C., and Wiley, R.G. 1996. Loss of nucleus basilis magnocellularis, but not septal, cholinergic neurons correlates with passive avoidance impairment in rats treated with 192-saporin. Neurosci. Lett. 203: 214-218.

Received January 7, 2005; accepted in revised form March 16, 2005.

\section{Learning \& Memory}




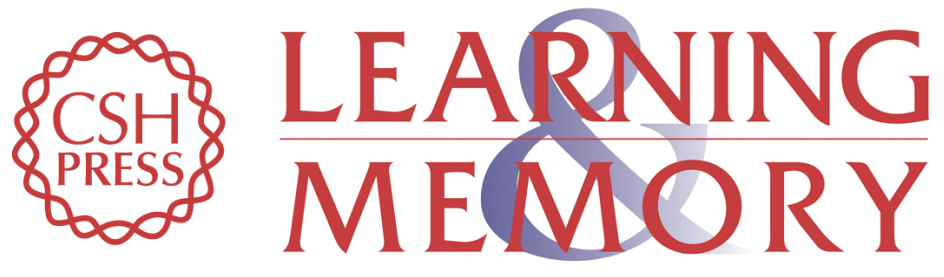

\section{Acetylcholine in the orbitofrontal cortex is necessary for the acquisition of a socially transmitted food preference}

Robert S. Ross, Jill McGaughy and Howard Eichenbaum

Learn. Mem. 2005, 12:

Access the most recent version at doi:10.1101/lm.91605

References This article cites 35 articles, 6 of which can be accessed free at:

http://learnmem.cshlp.org/content/12/3/302.full.html\#ref-list-1

License

Email Alerting Receive free email alerts when new articles cite this article - sign up in the box at the Service top right corner of the article or click here. 